\title{
Performance Measurement of Power Plants in the Existence of Weight Restrictions via Slacks Based Model
}

\author{
Reza Farzipoor Saen \\ Department of Industrial Management, Faculty of Management and Accounting, Islamic Azad \\ University-Karaj Branch, Karaj, Iran, P. O. Box: 31485-313
}

Tel: 0098 (261) 4418144-6

Fax: 0098 (261) 4418156

Email: farzipour@yahoo.com

\begin{abstract}
Purpose - The purpose of this paper is to suggest a model for evaluating the best power plants in the presence of weight restrictions.

Design/methodology/approach - This paper introduces a model, which is based on Slacks Based Model (SBM) (one of the data envelopment analysis models).

Findings - This paper depicts the power plant evaluation process through a data envelopment analysis model, while allowing for the incorporation of preferences of decision maker. The chief advantage of the proposed model is that it does not demand exact weights from the decision maker.
\end{abstract}

Originality/value - To the best of author's knowledge, there is not any reference that evaluates power plants by means of SBM in the presence of weight restrictions.

Keywords: Power plant evaluation, Data envelopment analysis, Assurance region

Paper Type Research paper

\section{Introduction}

Since the 1990s, globalization has increased enormously the competitive pressures on companies worldwide. In response, many of them have tried to boost simultaneously the efficiency and the quality of their production. Performance evaluations of companies are important to shareholders, managers and investors. Such evaluations indicate a number of important measures. For one thing, evaluations show the effects of decisions made in the past. Second, these evaluations also show the way financial structure of companies are formed. It is obvious that the main objective of performance evaluations is to find out whether the existing resources of companies are used efficiently. It has been recognized that business performance is a multidimensional construct, since it covers diverse purposes and types of 
organizations/levels. The single output to input financial ratios, such as, return on investment and return on sales, may be used as indices to characterize the financial performance. However, conventional referents of performance, whether they be measures of profitability, like return on investment and return on sales, or financial market measures, like the market to book ratio, are unsatisfactory discriminants of "excellence". Since a power plant's performance is a complex phenomenon requiring more than a single criterion to characterize it.

To measure performance of power plants, Data Envelopment Analysis (DEA) has found widespread applications. DEA is an efficiency modeling approach that can be described as an extension of simple input-to-output ratio analysis, rigorously generalized to handle multiple inputs and multiple outputs. DEA has been widely used to evaluate the relative efficiency of different Decision Making Units (DMUs). DEA uses mathematical modeling to calculate an “efficient frontier.” The frontier provides a yardstick against which to judge the comparative performance of all other firms or organizations that do not lie on the frontier. The efficient frontier is formed from the observed performances of the participating firms in the sample, determined by the relationships between the inputs and outputs of the firms in the sample. It is important to note that DEA calculations, because they are generated from actual observed data for each DMU, produce only relative efficiency measures. The relative efficiency of any DMU is calculated by forming the ratio of a weighted sum of outputs to a weighted sum of inputs, where the weights (multipliers) for both outputs and inputs are to be selected in a manner that calculates the efficiency measure of each DMU, subject to the constraint that no DMU can have a relative efficiency score greater than unity (Jha and Shrestha, 2006).

In this paper, DEA is chosen for the following reasons:

- It deals with individual cases;

- It does not require parametric assumptions, such as normality and equal variance;

- It can produce a single measure for each power plant;

- It can handle multiple-input and multiple-output situations;

- It places no restriction on the functional form of the input-output relationship;

- It focuses on revealed best-practice frontiers rather than on central tendency properties of empirical data;

Because of these advantages, DEA has been chosen as an appropriate approach to efficiency measurement of the power plants.

In original DEA formulations the assessed DMUs can freely choose the weights or values to be assigned to each input and output in a way that maximizes its efficiency, subject to this 
system of weights being feasible for all other DMUs. This freedom of choice shows the DMU in the best possible light, and is equivalent to assuming that no input or output is more important than any other.

The free imputation of input-output values can be seen as an advantage, especially as far as the identification of inefficiency is concerned. If a DMU (power plant) is free to choose its own value system and some other power plant uses this same value system to show that the first power plant is not efficient, then a stronger statement is being made. The advantages of full flexibility in identifying inefficiency can be seen as disadvantages in the identification of efficiency. An efficient power plant may become so by assigning a zero weight to the inputs and/or outputs on which its performance is worst. This might not be acceptable by Decision Makers (DMs) as well as by the analyst, who after spending time in a careful selection of inputs and outputs sees some of them being completely neglected by power plants.

DMs may have in power plant evaluation problems value judgments that can be formalized a priori, and therefore should be taken into account in power plant evaluation. These value judgments can reflect known information about how the factors used by the power plants behave, and/or "accepted" beliefs or preferences on the relative worth of inputs, outputs or even power plants. To avoid the problem of free (and often undesirable) specialization, input and output weights should be constrained in DEA.

Note that in traditional models, the weights are allocated in a crisp value, while in the proposed model; weights are defined in an interval. It is clear that interval definition of the weights for the DM is easier than the crisp weight assignment. As well, the bounds on factor weights in DEA's multiplier side problem are user-specified constants to reflect value judgments the DM wishes to incorporate in the assessment. They may relate to the perceived importance or worth of input and output factors.

The objective of this paper is to apply a model for evaluating power plants in the presence of weight restrictions. This paper depicts the power plant evaluation process through a DEA model, while allowing for the incorporation of DM's preferences. The chief advantage of the proposed model is that it does not demand exact weights from the DM.

This paper proceeds as follows. In Section 2, literature review is presented. Section 3 introduces the model which evaluates the power plants. Numerical example and concluding remarks are discussed in Sections 4 and 5, respectively.

\section{Literature review}

Various studies on the measurement of company performances are briefly summarized in the following subsections. 


\section{Translog and Cobb-Douglas frontiers}

Jaforullah (1999) estimated a number of translog and Cobb-Douglas frontier production models for the Bangladesh handloom textile industry to investigate its production technology and technical efficiency in production. Dashti (2003) evaluated inferences for efficiency of electric utilities based on Cobb-Douglas, translog and Fourier frontiers. Huang (2004) considered the measurement of firm's specific (in)efficiency while allowed for the possible heterogeneous technologies adopted by different firms. A flexible stochastic frontier model with random coefficients was proposed to distinguish technical inefficiency from technological differences across firms. However, these methodologies are parametric statistical methods that rely on central tendency rather than best multi-factor practice.

\section{Technique for Order Preference by Similarity to Ideal Solution}

Deng et al. (2000) formulated the inter-company comparison process as a multi-criteria analysis model, and presented an effective approach by modifying the Technique for Order Preference by Similarity to Ideal Solution (TOPSIS) for solving the problem. However, TOPSIS suffers from the subjectivity of weight assignment.

\section{Analytic network process}

Yurdakul (2003) formulated a multicriteria performance measurement system model using

the Analytic Network Process (ANP) to measure the long-term performance of a manufacturing firm. However, the main weakness of ANP is subjectivity of pairwise comparisons.

\section{Analytic hierarchy process}

Kahraman et al. (2004) compared catering firms by fuzzy Analytic Hierarchy Process (AHP). However, AHP has two main weaknesses. First subjectivity of AHP is a weakness. Second AHP could not include interrelationship within the criteria in the model.

\section{Artificial neural networks}

Delgado (2004) employed artificial neural networks for production frontier approximation of refuse collection services using a sample of Spanish (Catalonian) municipalities. Azadeh et al. (2007) proposed an efficiency frontier analysis method based on the adaptive neural network technique for evaluating 19 steam power plants in Iran for 2004. To estimate production function, artificial neural network method has been applied and for calculating the efficiency scores, a similar approach to econometric methods has been used. 


\section{Data envelopment analysis}

Pollitt (1996) used DEA to examine the relative productive efficiency of a sample of 78 publicly- and privately-owned nuclear power plants operating the year 1989. Sueyoshi (1997) developed a new DEA framework that systematically integrates eight efficiency concepts, scale economies, and returns to scale from the perspective of production and cost analyses. Also, he applied these results to 39 annual operations of Nippon Telegraph and Telephone. Cook et al. (1998) introduced the concept of hierarchical DEA, where efficiency can be viewed at various levels. They provided a means for adjusting the ratings of DMUs at one level to account for the ratings received by the group (into which these DMUs fall) at a higher level. They also developed models for aggregating different ratings for a DMU arising from different possible groupings. An application of these models to a set of power plants was given. Madu and Kuei (1998) demonstrated how to identify the best performers based on their efficiency scores and their outputs and also, how to identify specific areas of weaknesses for a particular firm. Cubbin and Tzanidakis (1998) identified and discussed important differences between regression analysis and DEA. The theoretical issues were illustrated with the help of an application of regression analysis and DEA on data from the regulated water industry in England and Wales. Friedman and Sinuany-Stern (1998) ranked fully 72 industrial branches in Israel in the DEA context. Nachum (1999) addressed issues related to the productivity measurement of firms using intangible input to produce intangible output. She examined the difficulties associated with the productivity measurement of such firms and suggested a measure that takes account of the unique attributes of the factors used in their production. This issue was examined with application to a professional service industry-management consulting- in which all inputs and outputs are intangible. Granderson and Linvill (1999) demonstrated how parametric and nonparametric (DEA) efficiency measures can be employed to produce benchmarks that account for the effects of regulation. They applied measurement techniques to an eleven-year panel of 20 U.S. interstate natural gas transmission companies and use the benchmarking measures to distinguish firms that perform well owing to a superior management of technology from firms that perform well owing to the effective management of the regulatory mechanism. Zhu (2000) developed tools for reconciling diverse measures which characterize the financial performance of the Fortune 500 companies. He employed DEA to determine a multi-factor financial performance model which inherently recognizes tradeoffs among various financial measures. Sengupta (2000) developed a DEA model that compares dynamic economic efficiency of firms in an industry. He proposed a two-stage decomposition of the decision model involving optimal investment paths in the first stage and 
minimal operating costs in the second stage. Olatubi and Dismukes (2000) measured cost efficiency opportunities for coal-fired electric generation facilities. They applied DEA to plant-specific information. Sueyoshi (2000) discussed how to incorporate future information into DEA. He presented a stochastic DEA model and then reformulated in the manner that the stochastic model can incorporate future information. Also, the model was applied to planning the restructure strategy of a Japanese petroleum company. Lam and Shiu (2001) applied DEA to measure the cross-sectional efficiency of China's thermal power generation. They also conducted a second stage regression analysis to identify the important factors that affect the performance of thermal power generation in China. Cricelli et al. (2002) applied DEA for measuring relative efficiency of 12 factories in the paper industry. Hollas et al. (2002) examined technical efficiency, economies of scale, and efficiency changes for gas distribution utilities during the period 1975-1994. Cowie (2002) examined the level of technical efficiency of 58 individual companies over 5 years to determine if mergers in practice have resulted in scale economies. Technical efficiency was estimated using DEA, under assumptions of constant and variable returns to scale. SubbaNarasimha et al. (2003) studied the performance effects of breadth and depth of technological knowledge on a sample of 29 U.S. pharmaceutical firms via DEA. Yoo (2003) proposed the methodology for the performance evaluation of Total Quality Management (TQM) by DEA. AHP was employed to quantify the weights of success factors for TQM. The proposed methodology was applied to the sample of 101 Korean firms. Talluri et al. (2003) applied DEA to measure the efficiency in the transformation of performance on manufacturing competitive dimensions into business performance in the automotive supplier industry. Braglia et al. (2003) presented a comprehensive analysis of the efficiency over time of five steel plants pertaining to one of the largest private groups in Italy. The analysis was carried out by DEA. Zheng et al. (2003) investigated the productivity performance of 600 state enterprises from 1980 to 1994 using DEA and Malmquist index. Rickards (2003) explained how to create a balanced scorecard with a reasonable number of indicators, set appropriate benchmarks for them, and evaluated overall management performance against those benchmarks by DEA. Barros (2004) employed DEA to analyze whether subsidization actually leads to improved technical and allocative efficiency in Portuguese defense-sector companies. Cook and Green (2004) presented a modified version of the DEA model to measure relative efficiency of a set of manufacturing plants in the steel molding and sheet steel industry. Using a panel data set of 361 German corporations for the period 1991-1996, Lehmann et al. (2004) tested the hypothesis that firms with more efficient governance structures have higher profitability. To determine efficiency, they compared firms with respect to ownership concentration, the identity of owners, capital 
structure, investment and firm growth by DEA. Narasimhan et al. (2004) proposed a twostage conceptual model to define flexibility and execution competencies. The relationship between these competencies was examined through the identification and description of potential flexibility drivers, flexibility measures, and firm level performance measures. Using the conceptual model as a basis for the analysis, they measured flexibility and execution competencies via a multistage DEA. The framework was empirically tested on a data set of 56 manufacturing firms. Chen and Ali (2004) provided an extension to the DEA-based Malmquist approach by further analyzing two Malmquist components. Their proposed approach not only reveals patterns of productivity change and presents a new interpretation along with the managerial implication of each Malmquist component, but also identifies the strategy shifts of individual DMUs based upon isoquant changes. The approach was illustrated with a set of Fortune Global 500 Computer and Office Equipment companies from 1991 to 1997. Omero et al. (2005) dealt with the problem of assessing the performance of a set of production units, simultaneously considering different kinds of information, yielded by a DEA, a qualitative data analysis and an expert assessment. Wu (2005) examined efficiency of Taiwan's steel industry based on a panel data during 1970-1996 by DEA. Serrano-Cinca et al. (2005) used DEA to the estimation of production functions, in order to assess efficiency in 40 dot com firms. Amirteimoori et al. (2006) improved the cost efficiency interval of a DMU by adjusting its observed inputs and outputs. They first proposed a DEA-based model with an interval efficiency in which the lower bound and upper bound of this interval, are respectively, the efficiency obtained from optimistic and pessimistic viewpoints. Then, units which are not prevail as cost efficient, are improved so that their lower bounds of cost efficiency become as large as possible and their upper bound attain the maximum value 1 . The particular application area investigated is that involving the gas companies of Iran. Again, Amirteimoori (2006) developed a new DEA with dynamic revenue efficiency. The proposed dynamic DEA model not only measures the efficiency of the whole periods, but also it provides the efficiency measure for each of the periods. An illustrative application of the methodology to a sample of gas companies from 11 regions of Iran in two periods was given. Barros (2006) analyzed the efficiency of a representative sample of Portuguese hypermarket and supermarket firms with a two-stage procedure. In the first stage, DEA is used to calculate technical and scale efficiency. In the second stage, a Tobit model is used to analyze the efficiency drivers. Cook and Zhu (2007) extended the DEA structure to apply to the more general setting where DMUs fall into distinct groups, and where all members of a group are to be treated uniformly in terms of multiplier allocation. The specific problem setting examined is the evaluation of relative efficiencies of 40 power plants. Based on the 145 largest watch 
and clock manufacturing firms in southern China, Wu et al. (2007) estimated technical efficiency by DEA. Düzakin and Düzakin (2007) developed a new extension of DEA called super Slacks Based Model (SBM), and applied it for ranking 500 major industrial enterprises of Turkey.

Although Düzakin and Düzakin (2007) proposed to employ SBM for ranking the companies, but they did not introduce a model which evaluates the companies in the presence of weight restrictions. This paper proposes a different use of SBM for power plant evaluation. To the best of author's knowledge, there is not any reference that evaluates power plants by means of SBM in the presence of weight restrictions. The approach presented in this paper has some distinctive features.

- The proposed model does not demand exact weights from the DM.

- Weights are opportunely restricted so that DEA's discriminatory power is augmented.

- The methodology is of the single-step type: power plant evaluation is a straightforward process carried out by DEA.

- An application of the methodology has been performed on a real set of data.

\section{Proposed method for power plant evaluation}

DEA proposed by Charnes et al. (1978) (CCR model) and developed by Banker et al. (1984) (BCC model) is an approach for evaluating the efficiencies of DMUs. One serious drawback of DEA applications in company evaluation has been the absence of DM judgment, allowing total freedom when allocating weights to input and output data of company under analysis. This allows companies to achieve artificially high efficiency scores by indulging in inappropriate input and output weights.

The most widespread method for considering judgments in DEA models is, perhaps, the weight restrictions inclusion. Weight restrictions allow for the integration of managerial preferences in terms of relative importance levels of various inputs and outputs. The idea of conditioning the DEA calculations to allow for the presence of additional information arose first in the context of bounds on factor weights in DEA's multiplier side problem. This led to the development of the cone-ratio (Charnes et al. 1989) and assurance region models (Thompson et al. 1990). Both methods constrain the domain of feasible solutions in the space of the virtual multipliers.

The input-oriented DEA models consider the possible (proportional) input reductions while maintaining the current levels of outputs. The output-oriented DEA models consider the 
possible (proportional) output augmentations while keeping the current levels of inputs. Charnes et al. (1985) developed the Additive model of DEA, which considers possible input decreases as well as output increases simultaneously. This model has no scalar measure (ratio efficiency). Although this model can discriminate between efficient and inefficient DMUs by the existence of slacks, it has no means of gauging the depth of inefficiency, similar to $\theta^{*}$ in the CCR model (Tone, 2001). Similar to $\theta^{*}$ in the CCR model, SBM with keeping Additive model properties, can gauge the depth of inefficiency.

Now, the proposed method for power plant evaluation is presented. The lower and upper bounds of the ratio of two inputs are as follow:

$$
l_{i j} \leq \frac{v_{j}}{v_{i}} \leq u_{i j}
$$

Similarly, the lower and upper bounds of the ratio of two outputs are as follow:

$$
L_{i j} \leq \frac{u_{j}}{u_{i}} \leq U_{i j}
$$

where $l_{i j}$ and $u_{i j}$ are user-specified constants to reflect value judgments the DM wishes to incorporate in the assessment. They may relate to the perceived importance or worth of input and output factors.

The multipliers formulation, with weight restrictions applying to all DMUs, is as below (Tone, 2001):

$\operatorname{Max} \quad \mathbf{u y}_{\mathbf{o}}-\mathbf{v x}_{\mathbf{0}}$;

s.t.

$$
\begin{aligned}
& \mathbf{u Y}-\mathbf{v X} \leq \mathbf{0} \text {; } \\
& \left(m \mathbf{x}_{\mathbf{o}}\right) \mathbf{v} \geq \mathbf{1} \text {; } \\
& \left(s \mathbf{y}_{\mathbf{0}}\right) \mathbf{u} \geq \mathbf{1}-\mathbf{v x}_{\mathbf{0}}+\mathbf{u y}_{\mathbf{0}} \text {; } \\
& \mathbf{v P} \leq \mathbf{0} \text {; } \\
& \mathbf{u Q} \leq \mathbf{0} \text {. }
\end{aligned}
$$

where there is a set of $n$ peer DMUs, $\left\{\mathrm{DMU}_{j}: j=1,2, \ldots, n\right\}$, which produce multiple outputs $y_{r j}(r=1,2, \ldots, s)$, by utilizing multiple inputs $x_{i j}(i=1,2, \ldots, m) . \mathbf{X}$ and $\mathbf{Y}$ are matrices of inputs and outputs, respectively. $\mathrm{DMU}_{o}$ is the $\mathrm{DMU}$ under consideration. $\mathrm{DMU}_{o}$ consumes $\mathbf{x}_{\boldsymbol{o}}$, the amount of input, to produce $\mathbf{y}_{\boldsymbol{o}}$, the amount of output. $u_{r}$ is the weight given to output $r$ and $v_{i}$ is the weight given to input $i$. 
$\mathbf{P}=\left(\begin{array}{lllccccc}l_{12} & -u_{12} & l_{13} & -u_{13} & \ldots & \ldots & \ldots & \ldots \\ -1 & 1 & 0 & 0 & \ldots & \ldots & \ldots & \ldots \\ 0 & 0 & -1 & 1 & \ldots & \ldots & \ldots & \ldots \\ \ldots & \ldots & \ldots & \ldots & \ldots & \ldots & \ldots & \ldots\end{array}\right)$

and

$\mathbf{Q}=\left(\begin{array}{cccccccc}L_{12} & -U_{12} & L_{13} & -U_{13} & \ldots & \ldots & \ldots & \ldots \\ -1 & 1 & 0 & 0 & \ldots & \ldots & \ldots & \ldots \\ 0 & 0 & -1 & 1 & \ldots & \ldots & \ldots & \ldots \\ \ldots & \ldots & \ldots & \ldots & \ldots & \ldots & \ldots & \ldots\end{array}\right)$

The matrices $\mathbf{P}$ and $\mathbf{Q}$ have dimensions $m \times n_{1}$ and $s \times n_{2}$, respectively, where $n_{1}$ and $n_{2}$ are determined by the number of assurance region constraints imposed.

The variables $\mathbf{v} \in R^{m}$ and $\mathbf{u} \in R^{s}$ can be interpreted as the virtual costs and prices of inputs and outputs, respectively. Model (1) aims to find the optimal virtual costs and prices for the $\mathrm{DMU}_{o}$ so that the virtual profit $\mathbf{u y}_{j}-\mathbf{v} \mathbf{x}_{j}$ does not exceed zero for any DMU (including $\mathrm{DMU}_{o}$ ), and maximizes the profit $\mathbf{u y}_{o}-\mathbf{v} \mathbf{x}_{o}$ for the $\mathrm{DMU}_{o}$ concerned. The second and third constraints of Model (1) restrict the feasible $\boldsymbol{v}$ and $\boldsymbol{u}$ to the positive values.

The dual of the Model (1) can be expressed as follows:

Min $\quad t-\frac{1}{m} \sum_{i=1}^{m} \frac{S_{i}^{-}}{x_{i o}}$

s.t.

$$
\begin{aligned}
& 1=t+\frac{1}{s} \sum_{r=1}^{s} \frac{S_{r}^{+}}{y_{r o}} ; \\
& t \mathbf{x}_{\mathbf{o}}=\mathbf{X} \mathbf{\Lambda}+\mathbf{S}^{-}-\mathbf{P \Phi} ; \\
& t \mathbf{y}_{\mathbf{o}}=\mathbf{Y} \mathbf{\Lambda}-\mathbf{S}^{+}+\mathbf{Q} \Pi ;
\end{aligned}
$$

$$
\begin{aligned}
& \boldsymbol{\Lambda} \geq \mathbf{0} \\
& \mathbf{S}^{-} \geq \mathbf{0} \\
& \mathbf{S}^{+} \geq \mathbf{0} \\
& t>0 \\
& \boldsymbol{\Phi} \geq \mathbf{0} \\
& \boldsymbol{\Pi} \geq \mathbf{0}
\end{aligned}
$$

where $t$ is a dual variable and $\Lambda, \boldsymbol{\Phi}, \Pi$ are dual vectors. Notice that $\Lambda, \boldsymbol{\Phi}$, and $\Pi$ are dual vectors of the first constraint, fourth constraint, and fifth constraint of the primal problem (the 
Model (1)), respectively. The vectors $\mathbf{S}^{-}$and $\mathbf{S}^{+}$indicate the input excess and output shortfall respectively, and are called slacks.

Let an optimal solution of Model (2) be $\left(t^{*}, \boldsymbol{\Lambda}^{*}, \mathbf{S}^{-*}, \mathbf{S}^{+*}, \mathbf{\Phi}^{*}, \boldsymbol{\Pi}^{*}\right)$. Then there is an optimal solution of the SBM as defined by

$$
\lambda^{*}=\frac{\Lambda^{*}}{t^{*}}, \mathbf{s}^{-*}=\frac{\mathbf{S}^{-*}}{t^{*}}, \mathbf{s}^{+^{*}}=\frac{\mathbf{S}^{+^{*}}}{t^{*}}, \varphi^{*}=\frac{\mathbf{\Phi}^{*}}{t^{*}}, \boldsymbol{\pi}^{*}=\frac{\boldsymbol{\Pi}^{*}}{t^{*}}
$$

A DMU is called "SBM-AR efficient" if the objective value of Model (2) is 1. The set of indices corresponding to positive $\lambda_{j}^{*}$ is called the reference set to $\mathrm{DMU}_{o}$.

In the next section, a numerical example is presented.

\section{Numerical example}

In this section, the proposed methodology is used for power plant evaluation, and is illustrated through a previously reported power plant evaluation problem (Azadeh et al., 2007). The power plant evaluation problem addressed in Azadeh et al. involves the evaluation of efficiency of 19 power plants (power plants) with respect to attribute including "gross production (in megawatt hour)", which is considered in some sense as output, and "installed capacity (in megawatt)", "internal consumption (in megawatt hour)" and "fuel consumption (in Tera Joule)", which are considered in some sense as inputs. Internal consumption is the amount of energy consumed within the power plant (for electrically powered equipments, etc.).

Note that the inputs and output selected in this paper are not exhaustive by any means. In an actual application of this methodology, DMs must carefully identify appropriate inputs and outputs measures to be used in the decision making process. Table 1 depicts the power plants' attributes. 
Table 1. Related attributes for 19 power plants in 2004

\begin{tabular}{|c|c|c|c|c|c|}
\hline \multirow{2}{*}{$\begin{array}{c}\text { Power plant } \\
\text { Name }\end{array}$} & \multirow{2}{*}{$\begin{array}{c}\text { DMU } \\
\text { no. }\end{array}$} & $\begin{array}{c}\text { Installed } \\
\text { capacity } \\
(\mathrm{MW})\end{array}$ & $\begin{array}{c}\text { Internal } \\
\text { consumption } \\
\text { (MW h) }\end{array}$ & $\begin{array}{c}\text { Fuel } \\
\text { consumption } \\
\text { (TJ) }\end{array}$ & $\begin{array}{c}\text { Gross } \\
\text { production } \\
\text { (MW h) }\end{array}$ \\
\hline Montazerghaem & 1 & 625.88 & 241139 & 30.95308 & 3297100 \\
\hline Besat & 2 & 247.5 & 139505 & 17.00441 & 1500253 \\
\hline Firoozi & 3 & 50 & 13039 & 3.412765 & 212403 \\
\hline Salimi & 4 & 1760 & 301276 & 107.1448 & \\
\hline Shazand & 5 & 1300 & 642909 & 57.30782 & 7438002 \\
\hline Rajaei & 6 & 1000 & 421015 & 54.61188 & 6342203 \\
\hline Beheshti & 7 & 240 & 85307 & 14.06063 & 1435991 \\
\hline Tabriz & 8 & 736 & 361080 & 42.82585 & 4341330 \\
\hline Mofatteh & 9 & 1000 & 390708 & 46.37235 & 5134547 \\
\hline Bistoon & 10 & 640 & 350154 & 38.2554 & 4210280 \\
\hline Ramin & 11 & 1890 & 636643 & 93.29557 & \\
\hline Madhaj & 12 & 290 & 81674 & 7.886569 & 922587 \\
\hline Bandarabbas & 13 & 1280 & 588855 & 73.2442 & 7196540 \\
\hline Zarand & 14 & 60 & 29698 & 4.322743 & 341402 \\
\hline Esfahan & 15 & 835 & 422673 & 52.77859 & 5621431 \\
\hline Montazeri & 16 & 1600 & 796262 & 102.4223 & \\
\hline Toos & 17 & 600 & 271901 & 37.45617 & 3831065 \\
\hline Mashhad & 18 & 120 & 63050 & 7.955432 & 665887 \\
\hline Iranshahr & 19 & 256 & 140940 & 15.76105 & 1492847 \\
\hline
\end{tabular}

According to the decision of DM, a constraint on the weights $v_{1}$ and $v_{2}$ is imposed:

$$
0.5 \leq \frac{v_{1}}{v_{2}} \leq 2
$$

Applying Model (2), the efficiency scores of power plants (DMUs) have been presented in Table 2. Model (2) identified power plants 4, 5, 6, 10, and 15 to be efficient with a relative efficiency score of 1. 
Table 2. Efficiency scores

\begin{tabular}{|c|c|c|}
\hline $\begin{array}{c}\text { Power plant } \\
\text { Name }\end{array}$ & DMUs & $\begin{array}{c}\text { Efficiency } \\
\text { scores }\end{array}$ \\
\hline Montazerghaem & 1 & .85985 \\
\hline Besat & 2 & .79338 \\
\hline Firoozi & 3 & .84944 \\
\hline Salimi & 4 & 1 \\
\hline Shazand & 5 & 1 \\
\hline Rajaei & 6 & 1 \\
\hline Beheshti & 7 & .92217 \\
\hline Tabriz & 8 & .838757 \\
\hline Mofatteh & 9 & .86655 \\
\hline Bistoon & 10 & 1 \\
\hline Ramin & 11 & .6795 \\
\hline Madhaj & 12 & .75696 \\
\hline Bandarabbas & 13 & .8079 \\
\hline Zarand & 14 & .7303 \\
\hline Esfahan & 15 & 1 \\
\hline Montazeri & 16 & .765 \\
\hline Toos & 17 & .94656 \\
\hline Mashhad & 18 & .7242 \\
\hline Iranshahr & 19 & .7858 \\
\hline
\end{tabular}

The entire efficiency scores for power plants are presented in Fig. 1. Fig. 1 implies that there is not the problem of a loss of discrimination power, and the data utilized in Model (2) is reasonable. Notice that the outcome of the proposed model is an efficiency score equal to one to efficient DMUs and less than one to inefficient DMUs. So, for inefficient DMUs a ranking is given but efficient DMUs can not be ranked. One problem that has been discussed frequently in the DMUs ranking literature, has been the lack of discrimination in DEA applications, in particular when there are insufficient DMUs or the number of inputs and outputs is too high relative to the number of DMUs. For more discussion, please see Farzipoor Saen (2008), Farzipoor Saen and Azadi (2009).

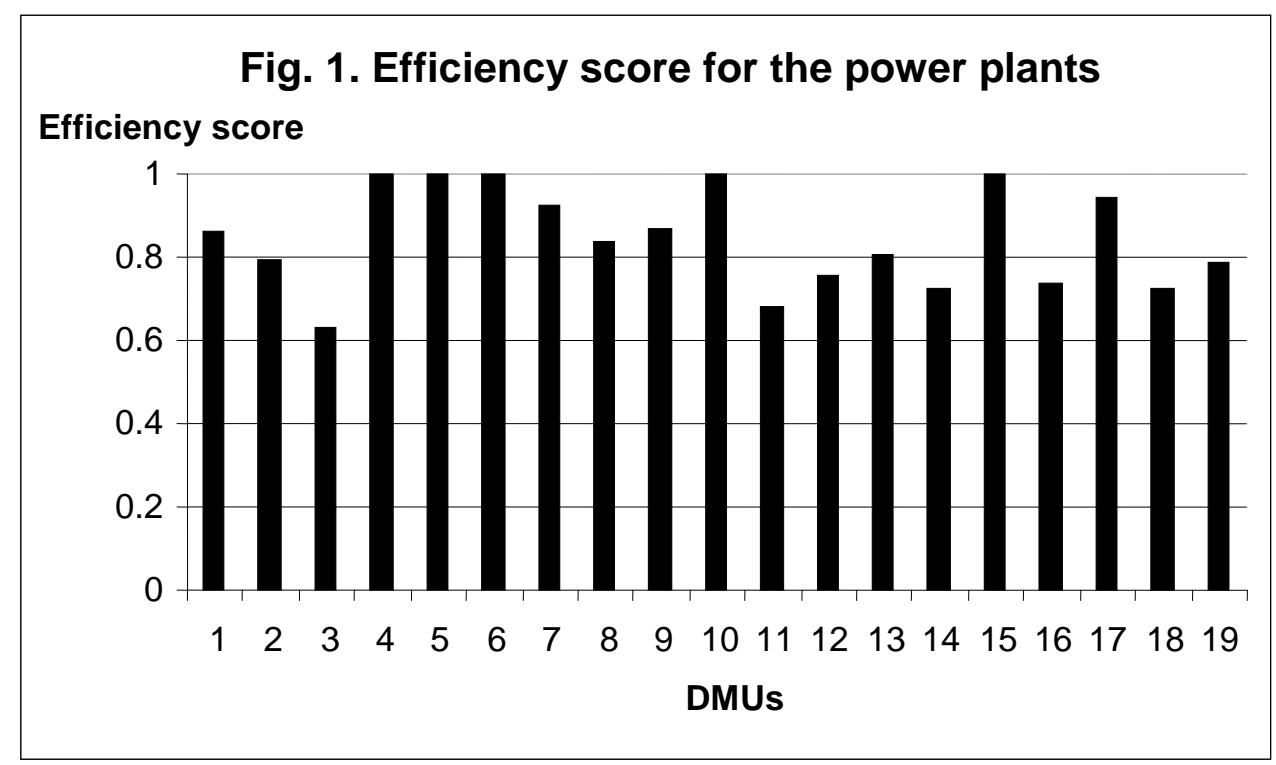


Also, Model (2) permits to identify the reference power plants which are the benchmarks in determining the power plant's efficiency. This would be a critical piece of information when a power plant is to improve efficiency, since the reference power plants become models to follow. Table 3 presents the reference power plants. The power plants 4, 5, 6, 10, and 15 are as the reference power plants. As mentioned before, the set of indices corresponding to positive $\lambda_{j}^{*}$ is called the reference set to $\mathrm{DMU}_{o}$, i.e., $\lambda_{4}^{*}, \lambda_{5}^{*}, \lambda_{6}^{*}, \lambda_{10}^{*}$, and $\lambda_{15}^{*}$ for $\mathrm{DMU}_{o}$ are positive.

Table 3. Reference power plants

\begin{tabular}{|c|c|}
\hline $\begin{array}{c}\text { Power plant } \\
\text { Name }\end{array}$ & DMUs \\
\hline Salimi & 4 \\
\hline Shazand & 5 \\
\hline Rajaei & 6 \\
\hline Bistoon & 10 \\
\hline Esfahan & 15 \\
\hline
\end{tabular}

Input excesses and output shortfalls can be determined by Model (2), which is displayed in Table 4. As discussed earlier, the vectors $\mathbf{S}^{-*}$ and $\mathbf{S}^{+^{*}}$ indicate the input excess and output shortfall, respectively. These vectors suggest that the efficiency of $\mathrm{DMU}_{o}$ can be improved if the input excesses recorded in $\mathbf{S}^{-*}$ are eliminated. Similarly efficiency can be attained if the output values are augmented by the output shortfalls in $\mathbf{S}^{\mathbf{+}^{*}}$. Thus, we have a method for improving an inefficient power plant. 
Table 4. Input excesses and output shortfalls

\begin{tabular}{|c|c|c|c|c|c|}
\hline \multirow[b]{2}{*}{$\begin{array}{l}\text { Power plant } \\
\text { Name }\end{array}$} & \multirow[b]{2}{*}{ DMUs } & \multicolumn{3}{|c|}{ Input excesses } & \multirow{2}{*}{$\begin{array}{c}\begin{array}{c}\text { Output } \\
\text { shortfalls }\end{array} \\
\begin{array}{c}\text { Gross } \\
\text { production } \\
\text { (MW h) }\end{array}\end{array}$} \\
\hline & & $\begin{array}{l}\text { Installed } \\
\text { capacity } \\
(\mathrm{MW})\end{array}$ & $\begin{array}{c}\text { Internal } \\
\text { consumption } \\
(\mathrm{MW} \mathrm{h})\end{array}$ & $\begin{array}{c}\text { Fuel } \\
\text { consumption } \\
\text { (TJ) }\end{array}$ & \\
\hline Montazerghaem & 1 & 85 & 68789 & 0 & 0 \\
\hline Besat & 2 & 0 & 63703 & 2.8 & 0 \\
\hline Firoozi & 3 & 0 & 4480 & .37 & 74162 \\
\hline Beheshti & 7 & 0 & 19491 & .07 & 0 \\
\hline Tabriz & 8 & 6 & 171723 & 0 & 0 \\
\hline Mofatteh & 9 & 172.4 & 89070 & 0 & 0 \\
\hline Ramin & 11 & 484.6 & 396072 & 7.7 & 0 \\
\hline Madhaj & 12 & 143.4 & 19152.8 & 0 & 0 \\
\hline Bandarabbas & 13 & 51.1 & 315861.9 & 0 & 0 \\
\hline Zarand & 14 & 0 & 19427 & .67 & 2477 \\
\hline Montazeri & 16 & 0 & 522374 & 5 & 331020 \\
\hline Toos & 17 & 0 & 13670 & 4 & 0 \\
\hline Mashhad & 18 & 4 & 43162 & 1 & 0 \\
\hline Iranshahr & 19 & 0 & 86636 & .4 & 0 \\
\hline
\end{tabular}

\section{Concluding remarks}

Owing to the increasing competitive pressure, resulting from the globalization of activities and markets, companies have to reorient their strategies, operations, processes and procedures to remain competitive. However, to achieve such competitive standing, these companies must be able to measure the different facets of their performance. Without the ability to understand and measure performance, benchmarking efforts aimed at deploying the best practices will not bear fruits. This paper suggested a model for evaluating the best power plants in the presence of weight restrictions. This paper not only sets best practice benchmarks for power plants but also helps to identify the areas that need attention and thus aid in better management of the power plants. The study also leads to insights in the operations of power plants and the causes of their inefficiency.

The problem considered in this study is at initial stage of investigation and many further researches can be done based on the results of this paper. Some of them are as below:

Similar research can be repeated for dealing with ordinal data and bounded data. Another research topic will be extending the proposed model for ranking efficient DMUs.

\section{Acknowledgments}

The author wishes to thank two anonymous reviewers for their valuable suggestions and comments. 


\section{References}

Amirteimoori, A. (2006), "Data envelopment analysis in dynamic framework”, Applied Mathematics and Computation, Vol. 181 No. 1, pp. 21-28.

Amirteimoori, A., Kordrostami, S. and Rezaitabar, A. (2006), “An improvement to the cost efficiency interval: a DEA-based approach”, Applied Mathematics and Computation, Vol. 181 No. 1, pp. 775-781.

Azadeh, A., Ghaderi, S. F., Anvari, M., Saberi, M. and Izadbakhsh, H. (2007), “An integrated artificial neural network and fuzzy clustering algorithm for performance assessment of decision making units”, Applied Mathematics and Computation, Vol. 187 No. 2, pp. 584-599.

Banker, R. D., Charnes, A. and Cooper, W. W. (1984), "Some methods for estimating technical and scale inefficiencies in data envelopment analysis”, Management Science, Vol. 30 No. 9, pp. 1078-1092.

Barros, C. P. (2004), “Measuring performance in defense-sector companies in a small NATO member country”, Journal of Economic Studies, Vol. 31 No. 2, pp. 112-128.

Barros, C. P. (2006), "Efficiency measurement among hypermarkets and supermarkets and the identification of the efficiency drivers”, International Journal of Retail \& Distribution Management, Vol. 34 No. 2, pp. 135-154.

Braglia, M., Zanoni, S. and Zavanella, L. (2003), "Measuring and benchmarking productive systems performances using DEA: an industrial case”, Production Planning \& Control, Vol. 14 No. 6, pp. 542-554.

Charnes, A., Cooper, W. W., Golany, B., Seiford, L. M. and Stutz, J. (1985), "Foundation of data envelopment analysis and Pareto-Koopmans empirical production functions”, Journal of Econometrics, Vol. 30 Nos 1-2, pp. 91-107.

Charnes, A., Cooper, W. W. and Rhodes, E. (1978), "Measuring the efficiency of decision making units”, European Journal of Operational Research, Vol. 2 No. 6, pp. 429-444. 
Charnes, A., Cooper, W. W., Wei, Q. L. and Huang, Z. M. (1989), “Cone-ratio data envelopment analysis and multi-objective programming”, International Journal of Systems Sciences, Vol. 20 No. 7, pp. 1099-1118.

Chen, Y. and Ali, A. I. (2004), "DEA Malmquist productivity measure: new insights with an application to computer industry”, European Journal of Operational Research, Vol. 159 No. 1, pp. 239-249.

Cook, W. D., Chai, D., Doyle, J. and Green, R. (1998), "Hierarchies and groups in DEA”, Journal of Productivity Analysis, Vol. 10 No. 2, pp. 177-198.

Cook, W. D. and Green, R. H. (2004), "Multicomponent efficiency measurement and core business identification in multiplant firms: a DEA model”, European Journal of Operational Research, Vol. 157 No. 3, pp. 540-551.

Cook, W. D. and Zhu, J. (2007), "Within-group common weights in DEA: an analysis of power plant efficiency”, European Journal of Operational Research, Vol. 178 No. 1, pp. 207216.

Cowie, J. (2002), “Acquisition, efficiency and scale economies: an analysis of the British bus industry”, Transport Reviews, Vol. 22 No. 2, pp. 147-157.

Cricelli, L., Gastaldi, M. and Levialdi, N. (2002), "Efficiency measurement of factories via data envelopment analysis”, SAMS, Vol. 42 No. 10, pp. 1521-1536.

Cubbin, J. and Tzanidakis, G. (1998), "Regression versus data envelopment analysis for efficiency measurement: an application to the England and Wales regulated water industry”, Utilities Policy, Vol. 7 No. 2, pp. 75-85.

Dashti, I. (2003), “Inference from concave stochastic frontiers and the covariance of firm efficiency measures across firms”, Energy Economics, Vol. 25 No. 6, pp. 585-601.

Delgado, F. J. (2004), “Efficiency in public sector: a neural network approach”, Proceedings of $10^{\text {th }}$ International Conference on Computing in Economics and Finance, The Netherlands. 
Deng, H., Yeh, C. H. and Willis, R. J. (2000), “Inter-company comparison using modified TOPSIS with objective weights”, Computers \& Operations Research, Vol. 27 No. 10, pp. 963-973.

Düzakin, E. and Düzakin, H. (2007), “Measuring the performance of manufacturing firms with super slacks based model of data envelopment analysis: an application of 500 major industrial enterprises in Turkey”, European Journal of Operational Research, Vol. 182 No. 3, pp. 1412-1432.

Farzipoor Saen, R. (2008), "Using super-efficiency analysis for ranking suppliers in the presence of volume discount offers”, International Journal of Physical Distribution \& Logistics Management, Vol. 38 No. 8, pp. 637-651.

Farzipoor Saen, R. and Azadi, M. (2009), “The use of super-efficiency analysis for strategy ranking”, International Journal of Society Systems Science, Vol. 1 No. 3, pp. 281-292.

Friedman, L. and Sinuany-Stern, Z. (1998), “Combining ranking scales and selecting variables in the DEA context: the case of industrial branches”, Computers \& Operations Research, Vol. 25 No. 9, pp. 781-791.

Granderson, G. and Linvill, C. (1999), "Parametric and nonparametric approaches to benchmarking the regulated firm”, Journal of Productivity Analysis, Vol. 12 No. 3, pp. 211231.

Hollas, D. R., Macleod, K. R. and Stansell, S. R. (2002), “A data envelopment analysis of gas utilities efficiency”, Journal of Economics and Finance, Vol. 26 No. 2, pp. 123-137.

Huang, H. C. (2004), "Estimation of technical inefficiencies with heterogeneous technologies”, Journal of Productivity Analysis, Vol. 21 No. 3, pp. 277-296.

Jaforullah, M. (1999), "Production technology, elasticity of substitution and technical efficiency of the handloom textile industry of Bangladesh”, Applied Economics, Vol. 31 No. 4, pp. 437-442. 
Jha, D. K. and Shrestha, R. (2006), "Measuring efficiency of hydropower plants in Nepal using data envelopment analysis”, IEEE Transactions on Power Systems, Vol. 21 No. 4, pp. 1502-1511.

Kahraman, C., Cebeci, U. and Ruan, D. (2004), "Multi-attribute comparison of catering service companies using fuzzy AHP: the case of Turkey”, International Journal of Production Economics, Vol. 87 No. 2, pp. 171-184.

Lam, P. L. and Shiu, A. (2001), “A data envelopment analysis of the efficiency of China's thermal power generation”, Utilities Policy, Vol. 10 No. 2, pp. 75-83.

Lehmann, E., Warning, S. and Weigand, J. (2004), “Governance structures, multidimensional efficiency and firm profitability”, Journal of Management and Governance, Vol. 8 No. 3, pp. 279-304.

Madu, C. N. and Kuei, C. H. (1998), “Application of data envelop analysis in benchmarking”, International Journal of Quality Science, Vol. 3 No. 4, pp. 320-327.

Nachum, L. (1999), “The productivity of intangible factors of production: some measurement issues applied to Swedish management consulting firms”, Journal of Service Research, Vol. 2 No. 2, pp. 123-137.

Narasimhan, R., Talluri, S. and Das A. (2004), "Exploring flexibility and execution competencies of manufacturing firms”, Journal of Operations Management, Vol. 22 No. 1, pp. 91-106.

Olatubi, W. O. and Dismukes, D. E. (2000), “A data envelopment analysis of the levels and determinants of coal-fired electric power generation performance”, Utilities Policy, Vol. 9 No. 2, pp. 47-59.

Omero, M., D’Ambrosio, L., Pesenti, R. and Ukovich, W. (2005), “Multiple-attribute decision support system based on fuzzy logic for performance assessment”, European Journal of Operational Research, Vol. 160 No. 3, pp. 710-725. 
Pollitt, M. G. (1996), “Ownership and efficiency in nuclear power production”, Oxford Economic Papers, Vol. 48 No. 2, pp. 342-360.

Rickards, R. C. (2003), "Setting benchmarks and evaluating balanced scorecards with data envelopment analysis”, Benchmarking: An International Journal, Vol. 10 No. 3, pp. 226-245.

Sengupta, J. K. (2000), “Comparing dynamic efficiency using a two-stage model”, Applied Economics Letters, Vol. 7 No. 8, pp. 521-523.

Serrano-Cinca, C., Fuertes-Callen, Y. and Mar-Molinero, C. (2005), "Measuring DEA efficiency in internet companies”, Decision Support Systems, Vol. 38 No. 4, pp. 557-573.

SubbaNarasimha, P. N., Ahmad, S. and Mallya, S. N. (2003), “Technological knowledge and firm performance of pharmaceutical firms”, Journal of Intellectual Capital, Vol. 4 No. 1, pp. 20-33.

Sueyoshi, T. (1997), "Measuring efficiencies and returns to scale of Nippon telegraph \& telephone in production and cost analyses”, Management Science, Vol. 43 No. 6, pp. 779-795.

Sueyoshi, T. (2000), "Stochastic DEA for restructure strategy: an application to a Japanese petroleum company”, Omega, Vol. 28 No. 4, pp. 385-398.

Talluri, S., Vickery, S. K. and Droge, C. L. (2003), "Transmuting performance on manufacturing dimensions into business performance: an exploratory analysis of efficiency using DEA”, International Journal of Production Research, Vol. 41 No. 10, pp. 2107-2123.

Thompson, R. G., Langemeier, L. N., Lee, C. T., Lee, E. and Thrall, R. M. (1990), “The role of multiplier bounds in efficiency analysis with application to Kansas farming”, Journal of Econometrics, Vol. 46 Nos 1-2, pp. 93-108.

Tone, K. (2001), “A slacks-based measure of efficiency in data envelopment analysis”, European Journal of Operational Research, Vol. 130 No. 3, pp. 498-509.

Wu, H. L. (2005), “A DEA approach to understanding the performance of Taiwan's steel industries 1970 1996”, Asia Pacific Management Review, Vol. 10 No. 6, pp. 349-356. 
Wu, Z. B., Yeung, G., Mok, V. and Han, Z. (2007), "Firm-specific knowledge and technical efficiency of watch and clock manufacturing firms in China”, International Journal of Production Economics, Vol. 107 No. 2, pp. 317-332.

Yoo, H. (2003), “A study on the efficiency evaluation of total quality management activities in Korean companies”, Total Quality Management, Vol. 14 No. 1, pp. 119-128.

Yurdakul, M. (2003), "Measuring long-term performance of a manufacturing firm using the analytic network process (ANP) approach”, International Journal of Production Research, Vol. 41 No. 11, pp. 2501-2529.

Zheng, J., Liu, X. and Bigsten, A. (2003), “Efficiency, technical progress, and best practice in Chinese state enterprises (1980-1994)”, Journal of Comparative Economics, Vol. 31 No. 1, pp. 134-152.

Zhu J. (2000), “Multi-factor performance measure model with an application to Fortune 500 companies”, European Journal of Operational Research, Vol. 123 No. 1, pp. 105-124. 